\title{
Online Life Cycle Assessment for Fluid Power Manufacturing Systems - Challenges and Opportunities
}

\author{
Marcel Rückert ${ }^{1}$, Stephan Merkelbach, Raphael Alt and Katharina Schmitz \\ Institute for Fluid Power Drives and Systems, RWTH Aachen University, \\ Campus-Boulevard 30, D-52074 Aachen, Germany \\ ${ }^{1}$ marcel.rueckerteifas.rwth-aachen.de
}

\begin{abstract}
Increasing demands for highly flexible production, e.g. mass customization, as well as the production industries' search for new business models, enabled by big data, pose completely new requirements and challenges for modern components of manufacturing systems. Challenges range from plug and produce to digital twin as well as reconfiguration. To meet the requirements of customers and industry alike, components within a manufacturing line need to be smart to communicate with each other and support the operator during the whole life cycle. In order to optimize the value chain, transparent machine costs as well as the carbon footprint of a component and system are highly relevant. Because of their high power density and controllability, fluid power actuators are prime components in manufacturing systems. In this work, the product life cycle of a modern electro hydraulic actuator for state of the art manufacturing systems is defined. Based on this framework, an assessment is made on state of the art actuators with the focus on life cycle costing and the carbon footprint. Subsequently, requirements for future developments are derived for each part of the product life cycle.
\end{abstract}

Keywords: Life cycle assessment, Digital twin, Total cost of ownership, Carbon footprint, Fluid Power, Compact hydraulic drives

\section{Introduction}

Mass customization caused by the costumers' demand for highly individualized products as well as a shortening of the product life cycle poses new challenges for the manufacturing industry. These challenges can be met with flexible production systems, tansparent machine costs and smart components. In order to achieve smart production systems, the idea of "Industrial Internet of Things" (IIoT) or "Industrie 4.0" (I4.0) was introduced [1] with the goal to fuse computational power (embedded systems) and mechatronic systems to implement an internet based machinery network. One primary target is that information of all participating instances of a specific manufacturing process are available in real-time, so that an ideal value-added flow can be identified [2]. As an approach for the discription of IIoT, it can be categorized into four different aspects: Vertical integration, horizontal integration, 
integrated engineering and the human role [3,4]. With a succesful implementation of IIoT, the estimated reduction in part production costs are approximately $70 \%$, see [2].

Fluid power components play an important role in manufacturing machines due to their compact size and high power density. Another advantage compared to electromechanical drives is the simple realizability of linear motions with cylinders. Most of the times, fluid power components act as actuators for presses, injection molding machines and other highly relevant manufacuting systems [5]. Fig. 1 shows a commonly used electro hydraulic actuator (EHA) and the integration into a calibration press. The EHA itself consists of an electric motor, a pump, a switching valve, an accumulator and a cylinder, all located within close proximity to reduce installation space.

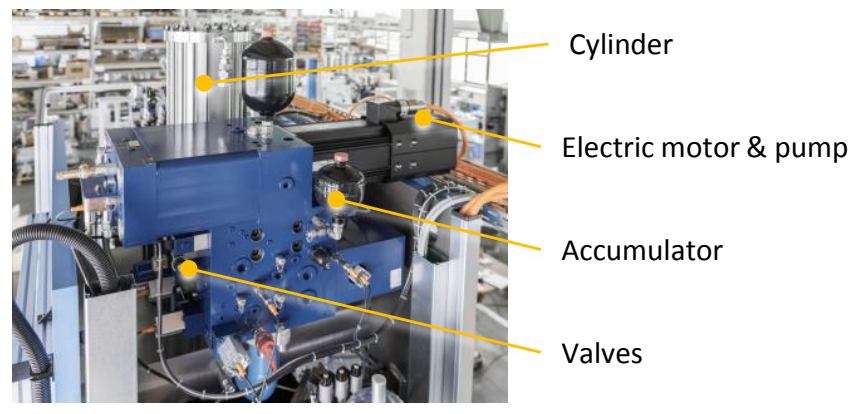

Fig. 1. Electro hydraulic actuator (EHA) integrated into a calibration press, after [6]

With increasing performance requirements, space optimization and increasing complexity of tasks, the correct planning of an EHA is highly relevant. Especially for the initial planning, information on life cycle costs of the product are important. Fig. $\mathbf{2}$ shows the typical stages: Planning, development, production, commissioning, usage and reconfiguration.

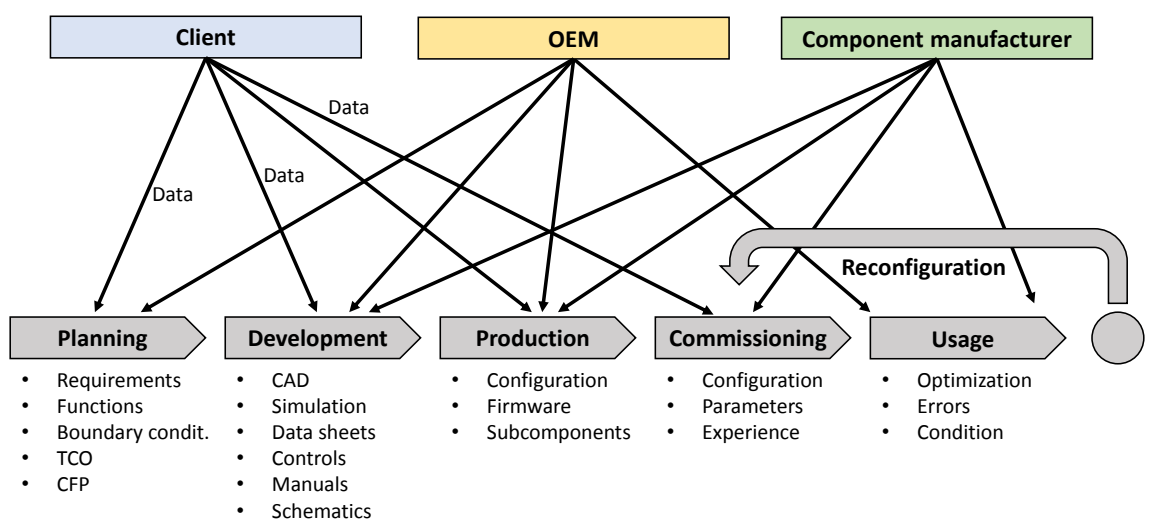

Fig. 2. Life cycle of an electro hydraulic actuator (EHA) for a smart manufacturing 
Planning - During the planning phase, boundary conditions and functions are defined that need to be fulfilled by the component. Based on these requirements, a suitable component can be selected. In case of an EHA, electro mechanical drives are an option as well. For this selection, additional soft factors such as the total cost of ownership (TCO) and the carbon footprint (PCF) influence the result, see [7]. Based on the assigned operation, a choice is made.

Development - The development of a component such as an EHA is highly complex due to the interaction of different subparts as well as the installation space restrictions. In order to use an optimal design, CAD-Software as well as 1D and multidimensional simulation approaches are chosen. Another important part is the selection of suitable subcomponents for the task.

Production - Production refers to the assembly and manufacturing of all necessary parts into a working EHA.

Commissioning - With an increasing component complexity, the commissioning is still predominantly done manually. This requires a deep integration of the commisioning engineer (CE) into the production process. Assistant systems can help the $\mathrm{CE}$ to reduce the level of complexity and support the transition of a CE into a system engineer $[4,8]$. After the commissioning, the EHA is fully operational and can be used for manufacturing purposes inside a machine.

Usage - During the usage, the condition in which the EHA is in can be monitored to ensure the functioning of the whole system as well as optimize and adjust production parameters. Highly flexible production requires low downtime. Therefore, predictive maintenance also plays an important role.

Reconfiguration - If the manufacturing process changes, or the EHA is supposed to be installed into another manufacturing machine, reconfiguration has to be done. Here, the dissassembly and refitting takes place. Afterwards, the commissioning has to be performed again, ensuring the connectivity with other components of the new manufacturing system.

During the product life cycle, different entities access and provide data regarding the component, see Fig. 2. These entities can be OEMs, component manufacturers or clients. Today, data and information is primarily stored decentrally regarding location and time with the need of manual data transfers. To make information more accessible for relevant entities and therefore make the usability of an EHA more efficient and flexible, fluid power components need to get smart.

In this paper, current technological possibilities for fluid power components regarding the online accessibility of data and life cycle assessment are analyzed. Afterwards, potential for necessary developments is introduced in order to define the role of fluid power components within intelligent manufacturing systems and mass customization. 


\section{State of the art}

With the goal being an intelligent manufacturing system, every instance of the value chain needs to be able to communicate with each other as well as generate data for condition monitoring purposes. As of today, a lot of manufacturing systems do have incompatible communication between the participants resulting in unstructured and locally distributed data. Therefore, the relations between each component is only known to the respective worker. This prevents the planning of optimized production routes for manufactured parts, making the whole system unflexible and the components passive elements in the value chain. A path of a part is only dictated by the technical staff, because many systems do not have any intelligence or experience. The comparison of the above described state I3.0 with the goal of I4.0 is depicted in Fig. 3. Here, lack of knowledge due to unstructured and only locally available data creates unflexible systems. With the need of mass customization and smart and green manufacturing systems, a modern information and communication technology (ICT) needs to be applied to all subsystems for a standardized communication between random participants of the manufacturing system. This results in the possibility of machine learning and intelligent systems, which can optimize the path of a part through the value chain autonomically, creating cyber physical systems (CPS).

\begin{tabular}{|c|c|}
\hline Lack of knowledge & 1.) Modern ICT \\
\hline $\begin{array}{l}\text { - Incompatible communication } \\
\text { " Unstructured data } \\
\text { " Information temporally and locally distributed } \\
\text { " Missing understanding of relations } \\
\text { " Systems have no experiences }\end{array}$ & $\begin{array}{l}\text { - Standardized communication between } \\
\text { random participants } \\
\text { - Semantic data } \\
\text { - Consistency and linkage of information } \\
\text { - Machine Learning, Big Data }\end{array}$ \\
\hline Unflexible action & Cyber-physical systems \\
\hline $\begin{array}{l}\text { " Passive elements } \\
\text { " Manual tasks done by technical staff }\end{array}$ & $\begin{array}{l}\text { - Horizontal value network (SoA) } \\
\text { - Smart components, digital functionality }\end{array}$ \\
\hline
\end{tabular}

Fig. 3. Comparison of Industry 3.0 and 4.0 [9]

Data gathered in this process as well as during the whole product life-cycle is necessary to assess and calculate transparent machine costs. The knowledge enables system engineers to efficiently design smart and green manufacturing systems. For this, a life cycle analysis together with the total cost of ownership and the carbon footprint of the component needs to be done.

In the following, state of the art methodologies to analyze a product life cycle are reviewed with regards to the total cost of ownership as well as the carbon footprint. 


\subsection{Life Cycle Analysis in Fluid Power}

In the past, different studies concerning the life cycles of fluid power equipment have been undertaken. These studies focus on two main impacts. The economic efficiency of different drives has to be evaluated and compared. Nowadays, the ecological impacts of the drives are added to the analysis as these factors become more and more important to manufacturers. In the future, the data necessary for the analysis of the economical as well as the ecological efficiency needs to be added to a digital twin of the EHA to ensure permanent monitoring.

Life Cycle Costing - The course of an analysis of the Life Cycle Costs (LCC) of different drives and some results will be discussed in the following.

There are many different approaches for the analysis of LCC. In general, the steps followed during the analysis are compareable in every approach. An industrial standard is given in [10]. This approach is shown in Fig. 4.

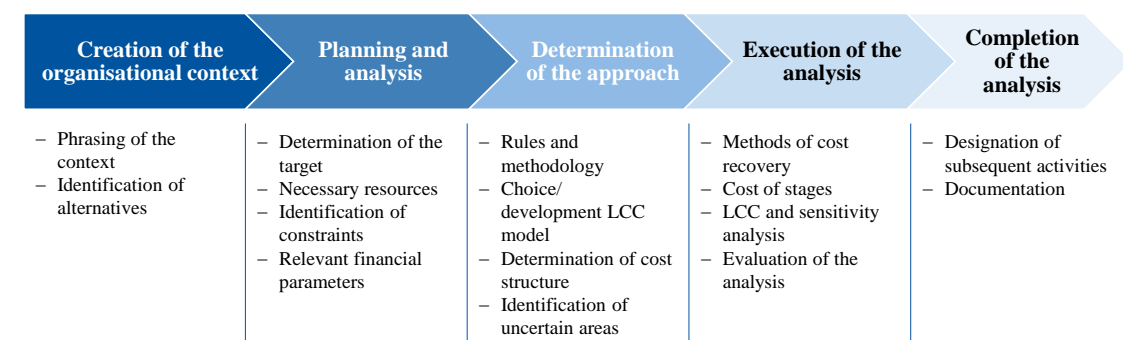

Fig. 4. Course of an LCC-analysis according to DIN EN 60300-3 [10]

No matter which approach is used, the LCC of every product is defined as the sum of five main cost blocks: Acquisition, installation, energy, maintenance \& repair and recycling. The partitions of these main blocks vary between different drives as well as between different applications. An exemplary comparative study between electromechanical $(\mathrm{EM})$ and pneumatic $(\mathrm{PN})$ linear drives was performed at the Institute for Fluid Power Drives and Systems (IFAS) in [7]. Results for the normalized LCC of these drives are shown in Fig. 5.

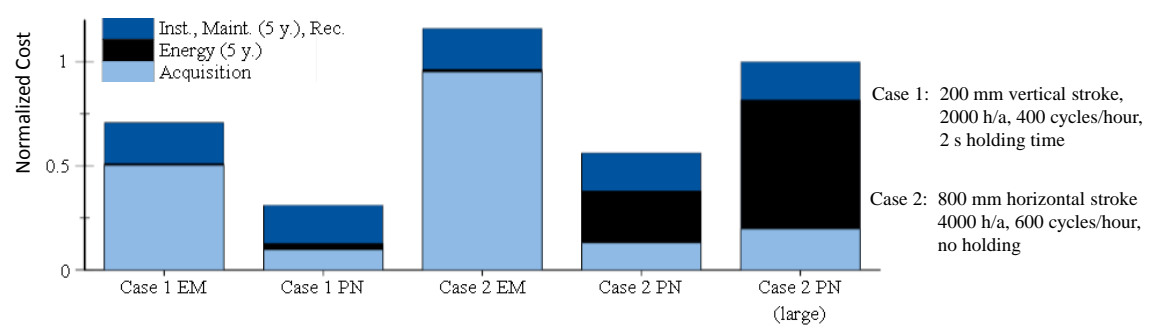

Fig. 5. Comparison of the normalized LCC for electromechanical and pneumatic linear drives as presented in [7] 
It is obvious, that the choice of drives has a large influence on the acquisition as well as on the energy costs whereas installation and maintenance are not of great importance for the comparison between the drives. Information about the driving energy or the necessary maintenance cycles to ensure availability should be made accessible in the digital twin to optimize the usage and to reduce overall costs for the industrial user.

Carbon Footprint Analysis - Due to the increasing importance of environmental matters and climate change in particular, nowadays, many companies are interested in the Product Carbon Footprint (PCF) of the drives used in their applications. Analogue to the estimation of the LCC of products, there are many different approaches for the estimation of the PCF. One approach is given in the international guideline ISO T/S 14067. This guideline presents an approach which is similar to a complete Life Cycle Analysis (LCA) but limited to the effects on global climate. In this case, the LCA has to be executed in four main steps, shown in Fig. 6.

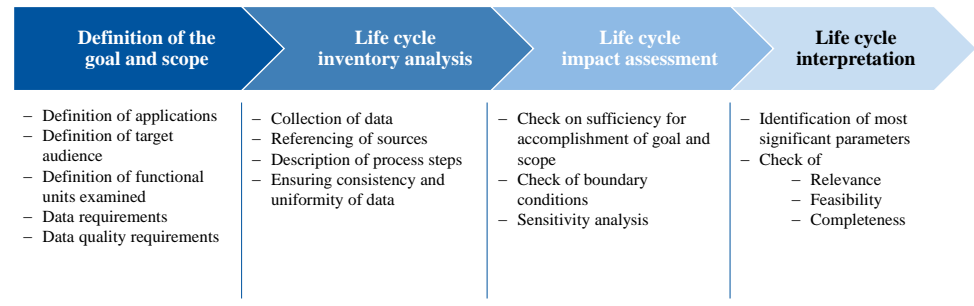

Fig. 6. Course of an LCA-analysis according to ISO 14044 and 14067 [11]

In order to realistically assess a components' total costs, access to data throughout the whole life-cycle needs to be available. Therefore, one of the most important steps towards intelligent manufacturing systems is the centrallized storage of data. In the following chapter, required information for each step are analyzed and listed as well as the necessity of having a digital twin is discussed.

\section{Digital twin and required data for EHAs}

In order to calculate the TCO and PFC in the planning phase, information regarding the product are required throughout its' life cycle. In each step, different information become relevant and it is of high importance that the access to information regarding future steps in the life cycle of a component are accessible for an optimal assessment of transparent costs.

Development \& Production - The development and production of a component is an interaction of the OEM as well as the (sub-) component manufacturer. Therefore definitions on what materials are used need to be communicated and stored. 
Addionally, the processing, energy used, assembly, production time and cost are influencing factors for life cycle costing.

Commissioning - During the commissioning, parameters used to tune the component such as valve configurations have to be recorded. This way, a holistic commissioning data-base can be introduced accounting for the collected experience of every individual commissioning engineer, supporting the path towards a system engineer. If data is availabale, the concept of plug and produce can be realized, see [12].

Usage - Data collected from the actual load cycles is highly relevant but also highly sensible since it gives information about the manufacturing process itself. Especially for the calculation of the TCO, informations on the load cycles (stroke, load, time, acceleration, number of duty cycles per time unit and energy used per load cycle) need to be recorded. Additional working appliances (compressed air, oil) as well as maintenance cycles and effort are of interest as well.

Reconfiguration - During reconfiguration, new boundary conditions and functions are defined. Therefore, no new data needs to be stored but information on usage data are required to parameterize the component towards its' new task.

To make data accessible, a digital twin of the real component is required.

Fig. 7 depicts the role of the digital twin within a product life cycle. Here, information of every step are stored in a digitally and every entity has access and can provide additional data. The digital twin is an exact copy of the component storing purpose and all interactions in a way, that OEMs and component manufacturers can get required data without interfering with the know-how of the manufacturing company.

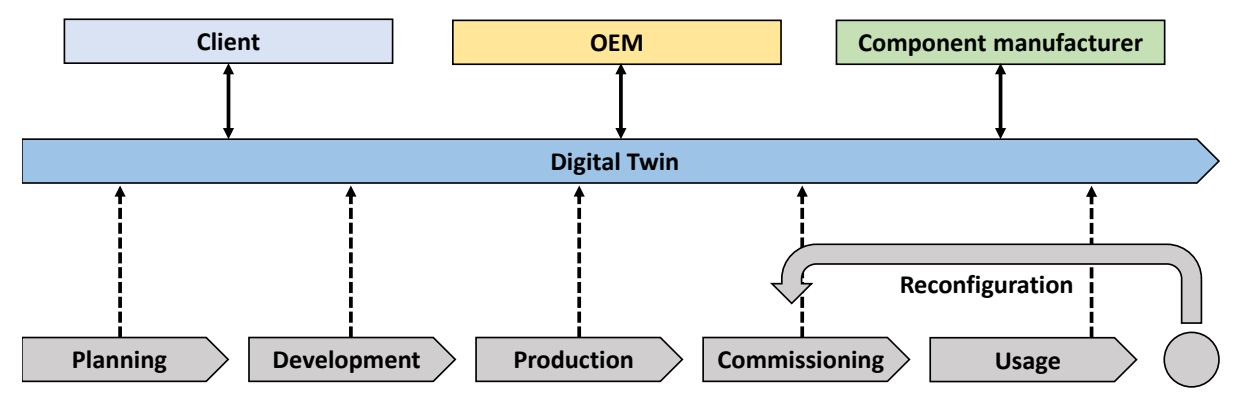

Fig. 7. A digital twin of an EHA helps to reduce complexity and provides structured information of the whole product life-cycle for future planning. 


\section{Summary and conclusion}

With the need of mass customization and highly felxible manufacutring systems as well as green manufacturing, components have to adapt to new requirements. As a prime actor, EHAs are used in a wide range of manufacturing machines. Due to the complexity and variety of subcomponents, an assessment regarding the life cycle cost of an EHA is difficult to make.

In this paper, a look into the different sections of the life cycle of an EHA was performed with a state of the art analysis regarding the TCO and PCF. Based on this analysis, requirements are formulated in order to gather data during the whole product life cycle. With the help of a digital twin, future planning and design of new fluid power actuators can be significantly improved and machine costs can be optimized based on the duty cycle.

To achieve transparent costs, challenges like big data and the resulting security issues regarding cycle times in manufacturing as well as uniform communication standards for all machine components need to be tackled. Fluid power components in general can help realising intelligent and green manufacturing systems.

\section{References}

1. Kagermann, H., et al., Industrie 4.0: Mit dem Internet der Dinge auf dem Weg zur 4. Industriellen Revolution, In: VDI Nachrichten, Nr. 13-2011, VDI Verlag GmbH (2011).

2. Wissenschaftliche Gesellschaft für Produktionstechnik (WGP), WGP-Standpunkt Industrie 4.0 (2016).

3. VDI/ VDE, Statusreport - Referenzarchitekturmodell Industrie 4.0 (RAMI4.0) (2015).

4. BITKOM, VDMA, ZVEI, Umsetzungsstrategie Industrie 4.0 (2015).

5. Michel, S., Weber, J., Energy-efficient electrohydraulic compact drives for low power applications, Proceedings of the Bath/ASME 2012 Symposium on Fluid Power and Motion Control FPMC2012, Bath, UK (2012)

6. N.N., https://www.boschrexroth.com/en/xc/industries/machinery-applications-andengineering/machine-tools-forming-and-separating/references/frey/frey, visited 04/19/18

7. Merkelbach, S., Murrenhoff, H. et al. Pneumatische und elektromechanische Linearantriebe - Ein Vergleich der TCO, O+P Oelhydraulik und Pneumatik (in German Language), (2017).

8. Kagermann, H., et al., Industrie 4.0: Mit dem Internet der Dinge auf dem Weg zur 4. Industriellen Revolution, In: VDI Nachrichten, Nr. 13-2011, VDI Verlag GmbH (2011)

9. Alt, R., et al., A SURVEY OF INDUSTRIAL INTERNET OF THINGS IN THE FIELD OF FLUID POWER - BASIC CONCEPT AND REQUIREMENTS FOR PLUG-AND-PRODUCE, Bath/ASME 2018 Symposium on Fluid Power and Motion Control FPMC2018, Bath, UK (2018) Unpublished

10. DIN - Deutsches Institut für Normung e.V. DIN EN 60300-3-3 Dependability management - Part 33: Application guide - Life cycle costing, Beuth Verlag (in German Language), Berlin, (2014).

11. DIN - Deutsches Institut für Normung e.V. DIN EN ISO 14044 Environmental management - Life cycle assessment - Requirements and guidelines, Beuth Verlag, Berlin, (2006).

12. Profanter, S, et al., „OPC UA for Plug \& Produce: Automatic Device Discovery using LDS-ME“, (2017). 